\title{
Article \\ Energy Key Performance Indicators for Mobile Machinery
}

\author{
Pedro Roquet ${ }^{1}$, Gustavo Raush ${ }^{2, *}\left(\mathbb{C}\right.$, Luis Javier Berne ${ }^{3}$, Pedro-Javier Gamez-Montero ${ }^{2}\left(\mathbb{C}\right.$ and Esteban Codina ${ }^{2}(\mathbb{D}$ \\ 1 ROQCAR SL, Antonio Figueras 68, 08551 Tona, Spain; pereroquet@hotmail.com \\ 2 CATMech, Department of Fluid Mechanics, Technical University of Catalonia, Colom 7, 08222 Terrassa, Spain; \\ pedro.javier.gamez@upc.edu (P.-J.G.-M.); esteban.codina@upc.edu (E.C.) \\ 3 IHBER, Polígono Malpica, Calle F, Nave 65, 50016 Zaragoza, Spain; ljberne@ihber.com \\ * Correspondence: gustavo.raush@upc.edu; Tel.: +34-93-739-82-24
}

check for updates

Citation: Roquet, P.; Raush, G.; Berne, L.J.; Gamez-Montero, P.-J.; Codina, E. Energy Key Performance Indicators for Mobile Machinery. Energies 2022, 15, 1364. https://doi.org/10.3390/ en15041364

Academic Editors: Eryk Remiorz and Piotr Cheluszka

Received: 30 December 2021

Accepted: 8 February 2022

Published: 14 February 2022

Publisher's Note: MDPI stays neutral with regard to jurisdictional claims in published maps and institutional affiliations.

Copyright: (c) 2022 by the authors. Licensee MDPI, Basel, Switzerland. This article is an open access article distributed under the terms and conditions of the Creative Commons Attribution (CC BY) license (https:// creativecommons.org/licenses/by/ $4.0 /)$.

\begin{abstract}
Mobile machinery manufacturers must face and deal with reducing fuel consumption, rising prices, and environmental pollution. The development of methods to evaluate the efficiency and effectiveness of the energy performance of hydraulically actuated systems has become a priority for researchers and OEMs, Original Equipment Manufacturers. In this paper, a new methodology that is based on Key Performance Indicators, KPI, is proposed with different goals: (i) to evaluate the energy performance and the monitoring of its evolution in the different stages of its life cycle (design, commissioning, optimization, retrofit, etc.); (ii) compare the energy levels between machines of different sizes and different brands in a benchmarking process; and (iii) establish a database that is state of the art, which facilitates setting achievable goals or limits for improvement. These KPI values can be deduced simply from the energy balances that were made from the experimental study of various machines over a relatively long period. This methodology has been applied to typical hydraulic systems for lifting and lowering loads that are used in a wide variety of mobile machines of different mechanical designs and sizes. Still, it can be included in the generic name of "loaders". A KPI's values for the three machines are presented in a dashboard as a decision-making tool.
\end{abstract}

Keywords: KPI; energy index; average energy index; energy balance; hydraulic systems; mobile machinery; dashboard; decision-making tool

\section{Introduction}

Mobile working machines (MWM) are often diesel-operated and they are essential nowadays in industry, for example mining, construction, forest harvesting, agriculture, and process and goods manufacturing machinery. In recent years, most MWM development projects are required to comply with restrictions on emission reductions due to stricter rules and needs to improve energy utilization energy losses. There is a general commitment, especially in the European Community (EC), on reducing energy consumption with a clear objective: $15 \% \mathrm{CO}_{2}$ reduction in 2025 and $30 \% \mathrm{CO}_{2}$ reduction in 2030 [1] compared with 2019 (before COVID period). This limits the energy consumption of off-road vehicles since fuel consumption is directly related to $\mathrm{CO}_{2}$ emissions. The ongoing debates about air quality in European cities are very likely going to lead to further reductions in emissions that are allowed by law. Possible scenarios include emission-free protection zones in and around urban and work areas. These measures will eventually also affect the applicability of mobile machinery. A main challenge for project managers is the trend towards hybrid diesel/electric units and even all-electric work machines.

In recent years, many technical papers have been published that propose different energy-saving systems, denominated R3 strategies (reducing, recovering, and regenerating) [2-5]. Various schemes of hydraulic systems, such as load-sensing system, independent metering, common pressure rail system, and system hybridization have been developed. Karpenko et al. [2], Ying Xiao Yu et al. [3], and Mahato et al. [6] provided an excellent and detailed review of a summary of the different energy saving strategies of a power hydraulic 
system with respect to energy saving potential. From these works the following outcomes were collected:

1- Process optimization strategies can allow an energy recovery of the order of $53 \%$ and a diesel savings potential of approximately $20-40 \%$,

2- controlled displacement systems (on an excavator) can reach levels of around $40 \%$ in diesel saving capacity,

3- constant pressure system (in braking systems) can reach levels of $8 \%$ waste energy recovery, and

4- the applicability of a soft switch concept can facilitate a throttling energy saving potential which can reach levels as high as $56-66 \%$

In general, project managers develop methodologies and templates that are specific to the manufacturing industry that they are dealing with. This allows project plans to become very comprehensive and highly repeatable, with the clear intent of increasing quality, reducing delivery costs, and reducing the time to deliver project results. In the last half of the past century, the Management by Objectives (MBO) approach dominated management. Drucked (1954) [7] first mentioned the MBO. This management philosophy became very popular in the 70s. Deming (1994) [8] criticized the perversion of viewing the "objective" as a priority item [8]. A new concept was born in the second half of 20th century, denominated project management (PM), where key performance indicators (KPI's) play a fundamental role $[9,10]$. KPI is a measure of achievement that is attributed to an individual, team, department, equipment, and plants. KPIs should be constructed using objectives by setting SMART (SMART: Specific, Measurable, Achievable, Relevant, Timely) principles and were generally developed as part of a performance management system.

High-level KPIs can be set on overall business performance while low-level KPIs can focus on sales, human resources, and other marketing processes. Equipment, plants, and construction industry KPI's are mainly used for benchmarking. This is a method of identifying poor performance and estimating improvement potential [11].

Normally, KPIs are used in the design process of components and machines, for example: monitoring design, cost, delivery time, etc. There are few cases where these indices are used to track the technical parameters, such as: mechanical or hydraulic losses, frictions forces, energy consumption, etc. This was signaled by May and Barletta when, in 2015, stated that "Developing of energy related KPI's at machine level " . . is the first gap of industrial needs [12-14]. There is no doubt that KPIs have enormous potential as a comparative method of machine performance and, consequently, a tool in monitoring continuous improvement [15].

This article attempts to focus on evaluating opportunities for improved energy efficiency using KPI's. We introduce the concept of energy design KPI as a measurable value that evaluates the success of component and machine design in meeting objectives for energetic efficiency. In that context, proposed methods to reduce losses and increase the energy efficiency of such machines are welcome. In another area, the consideration of these indices can help the adoption by operators of electric/hybrid technologies in mobile machinery and can facilitate the validation of prospective technological developments.

This paper is organized as follows. Section 1 presents the introduction of the work that is discussed in this paper. Section 2 is dedicated to defining the energy index and average energy index. Section 3 presents energy balance analysis. Sections 4 and 5 show examples about the use of average of the energy index as a key performance indicator including a summary dashboard. Finally, in Section 6, the conclusions about the KPI analysis are discussed.

\section{Definitions}

When we try to analyze or compare different machines that can perform the same or similar functions, it is interesting to investigate how energy is distributed in the different work cycles. A performance index, denominated "efficiency" has been used in most cases. Efficiency as a function of time $\eta(t)$ is normally defined as a ratio between the output $\left(\mathrm{P}_{\text {out }}\right)$ 
and input $\left(P_{\text {in }}\right)$ power. In our case, we are interested in the ratio between the total energy output and input, but, for a specific part of a cycle or for the full cycle (for example, along the cylinder stroke). For these reasons, in this paper two indexes have been defined: the energy index and the average energy index.

\subsection{Energy Index}

The energy index $W_{x}$ is a dimensionless parameter that is defined as the energy that is involved in the movement of a actuator from a position $s e_{1}$ to a position $s e_{2}=s e_{1}+\Delta s e$ divided by $Q_{0} \Delta t_{0} P_{r e f}$, where $Q_{0}$ is a constant flow that is supplied (for example, by a pump), $\Delta t_{0}$ is a time spends to go from $s e_{1}$ to $s e_{2}$, and $P_{r e f}$ is a reference pressure (we chose $P_{r e f}=1$ bar for simplicity).

Referring to Figure 1 (left), the energies that are involved in the upward movement of the boom cylinder moving from position $s e_{1}$ to position $s e_{2}$ can be defined as:

$$
\begin{gathered}
s e_{2}=s e_{1}+\Delta s e \\
W_{1 b}=\frac{\text { Energy of flowentering of base chamber } 1 b}{Q_{0} t_{0} P_{\text {ref }}}=\frac{P_{1 b}}{P_{\text {ref }}} \\
W_{1 t}=\frac{\text { Energy of flow out of base chamber } 1 t}{Q_{0} t_{0} P_{\text {ref }}}=\frac{P_{1 t} t_{0} Q_{1 t}}{Q_{0} t_{0} P_{r e f}}=\frac{Q_{1 t} P_{1 t}}{Q_{0} P_{r e f}} \\
W_{1 t}=\frac{P_{1 t} A_{1 t} s_{t}}{A_{1 b} s_{b} P_{r e f}}=\frac{P_{1 t}}{P_{r e f}} k \\
k=\frac{A_{1 t} s_{t}}{A_{1 b} s_{b}}
\end{gathered}
$$
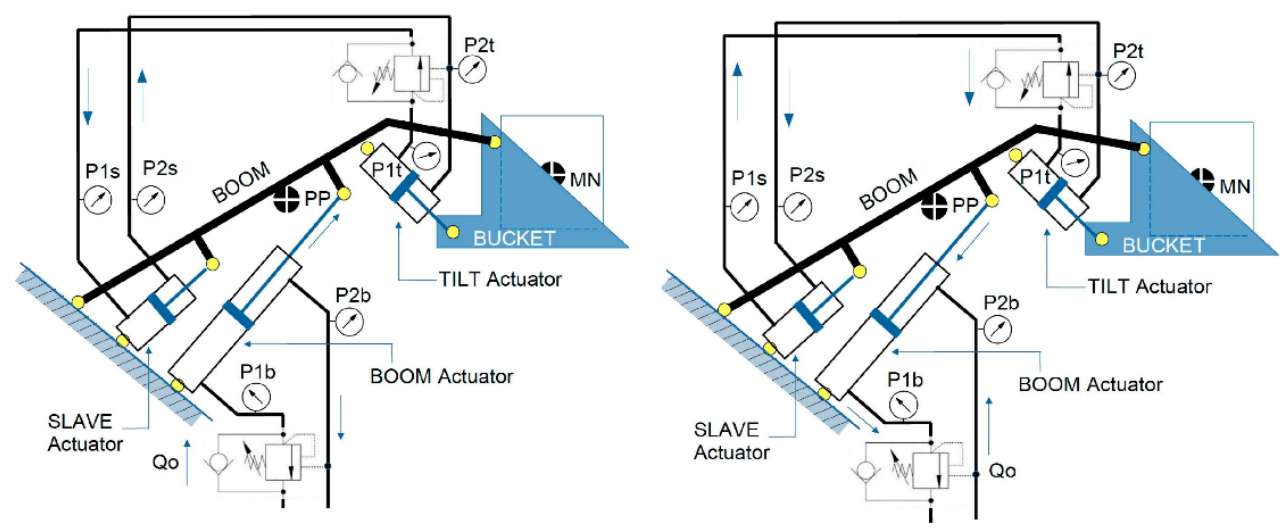

Figure 1. Scheme of a typical loader. (Left): upwards movement. (Right): downwards movement.

Analogously, referring to Figure 1 (right), for downwards movement, the energies that are involved in the downward movement from $s e_{1}=s e_{2}+\Delta s e$, are

$$
W_{1 b}=\frac{\text { Energy of flow } Q_{1 b} \text { out of chamber } 1 b}{Q_{0} t_{0} P_{\text {ref }}}=\frac{P_{1 b} Q_{1 b} t_{\text {down }}}{P_{\text {ref }} Q_{0} t_{0}}
$$

where, $\Delta t_{\text {down }}=r \Delta t_{0}$ and $r=A_{1 b} / A_{2 b}$ is area ratio of elevation actuator.

$$
\begin{gathered}
W_{1 b}=\frac{P_{1 b} r Q_{0} t_{\text {down }}}{Q_{0} r t_{\text {down }} P_{\text {ref }}}=\frac{P_{1 b}}{P_{\text {ref }}} \\
W_{2 b}=\frac{\text { Energy of flow entering of chamber } 2 b}{Q_{0} \Delta t_{0} P_{\text {ref }}}=\frac{P_{2 b} Q_{0} \Delta t_{\text {down }}}{P_{\text {ref }} Q_{0} \Delta t_{0}}=\frac{P_{2 b}}{r P_{\text {ref }}}
\end{gathered}
$$




$$
W_{2 t}=\frac{P_{2 t} Q_{10} t_{\text {down }}}{Q_{0} t_{0} P_{\text {ref }}}=\frac{P_{2 t} A_{2 t}\left(\frac{s_{t}}{t_{\text {down }}}\right) t_{\text {down }}}{A_{2 b}\left(\frac{s_{b}}{t_{\text {down }}}\right)\left(\frac{t_{\text {down }}}{r}\right)}
$$

On the other hand, the energy that is transferred to the load is equal to its potential energy raising. The mass that is involved is composed of the equivalent proper mass (bucket, arm, tilt cylinder, etc.), and the nominal mass (load). $M_{p p}$ is the symbol that is related to the whole mechanism mass, and $M_{N}$ points to the nominal mass.

$$
W_{M N}=\frac{\text { Increase of potential energy of nominal mass }}{Q_{0} \Delta t_{0} P_{\text {ref }}}=\frac{M_{N} g \Delta h}{Q_{0} \Delta t_{0} P_{r e f}}
$$

Note that $\Delta h$ sign modifies the incoming or outcoming potential energy.

$$
\begin{aligned}
Q_{0}{ }^{(u p)} & =\frac{\Delta s e}{\Delta t_{0}} A_{1 b} \Rightarrow(\text { upwards }) \\
Q_{0}{ }^{(\text {down })} & =\frac{\Delta s e}{\Delta t_{0}} A_{2 b} \Rightarrow(\text { downwards })
\end{aligned}
$$

Substituting $\mathrm{b}$ for its value and $Q_{0}$ for any of the two values corresponding to the up or down movement:

$$
\begin{aligned}
W_{M N} & =\frac{M_{N} g b}{A_{1 b} P_{r e f}} \\
W_{M N} & =\frac{M_{N} g b}{A_{2 b} P_{r e f}}
\end{aligned}
$$

where

$$
b=\frac{\Delta h}{\Delta s e}
$$

\subsection{Average Energy Index}

The average energy index $I W_{x}\left(s e_{i}\right)$ represents the average value of the energy index of a load movement with a stroke.

$$
I W_{x}\left(s e_{i}\right)=\frac{1}{s e_{i}} \int_{0}^{s e_{i}} W_{x} d s
$$

As an example, to explain and develop the concepts that are proposed in this paper, the activity of raising and lowering a load has been taken as an object of study. We have considered different machines (e.g., frontal loader, telehandler, and steer skid loader) that could generically be included under the common name of loaders; all have a self-leveling bucket system.

Of all the available ones, this study examined those that present a greater didactic value and cover a wider range of possibilities. This work is based on the data that were collected over the last few years in the experimental study of machines, components, and systems. Most of them are the result of laboratory appliances and prototypes that allow the incorporation of atypical components and hydraulic circuit architectures that were specifically chosen for research purposes [16]. It should be noted that no results came from one specific experiment with the purpose of validating the proposed KPIs. On the contrary, they are the basis for their development and, therefore, sometimes a dispersion of results may appear that would not occur in more controlled experimental conditions. We understand that this does not detract from the experimental validation, but rather adds value to its practical use in a real environment.

Figure 2 shows two topological schemes (A and B) that characterize the three machines that are considered. Of these, two machines are of type $\mathrm{A}$ and one machine of type B. For identification purposes, we named the three machines M1A, M2A, and M3B. All of them 
are of different sizes, even though they synchronize the bucket movement by the "slave actuator system." In the M1A and M2A units, the boom actuator retracts when raising, and in the M3B unit, the tilt actuator extends when raising.
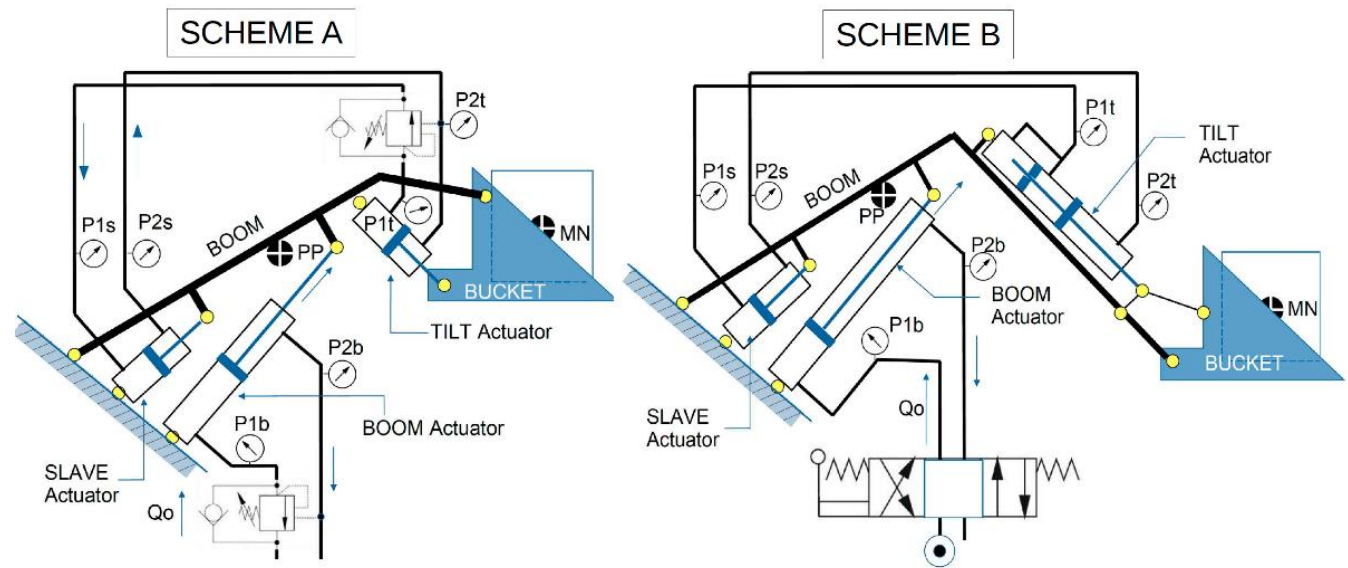

Figure 2. Schemes of the proposed machines (different topologies).

Customed hydraulic machines were instrumented at the experimental rigs that are owned at the CATMech-UPC labs. Dedicated sensors and transmitters were adapted to record the standard working cycle. Data were collected on the pressures, linear and angular positions, fluid temperatures at relevant points, and pump outflow. All were sampled at a rate of $1 \mathrm{kHz}$.

The data were collected by the RMC200 multi-axis motion controller from Delta Computer Systems, Inc. Figure 3 shows the typical graphs of the variables that were recorded as a function of time.
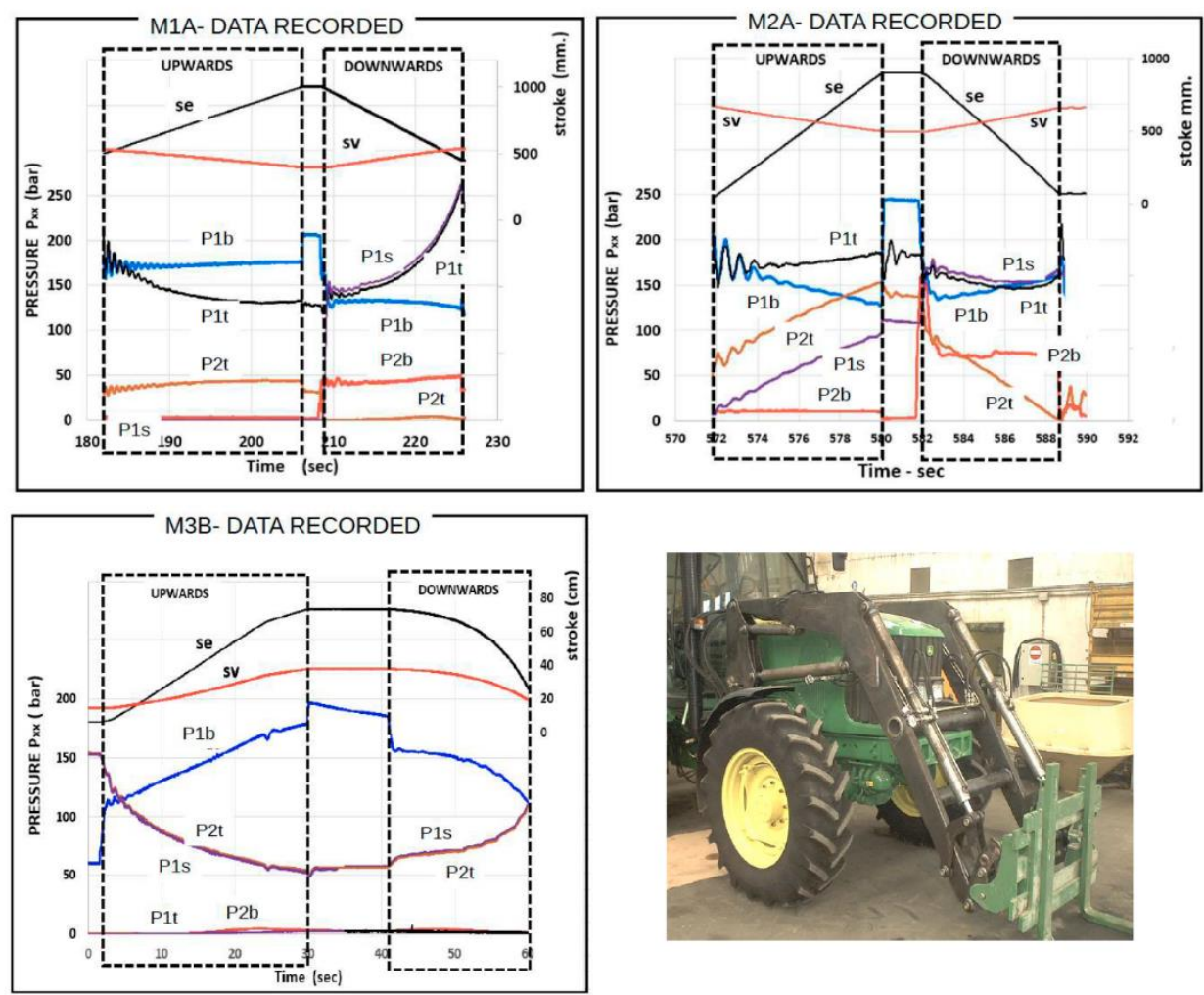

Figure 3. Typical graphs of the variables that were recorded as a function of time for the three proposed machines. 
Figure 4 presents examples of the plots corresponding to the energy index, $W x$, for different types of machines. This information is kinematically given by the evolution of the parameter " $\mathrm{b}$ ", and hydraulically by the evolution of the energy index, $W_{1 b}$, and may be condensed into a single parameter such as the slope of the adjusted trend line.
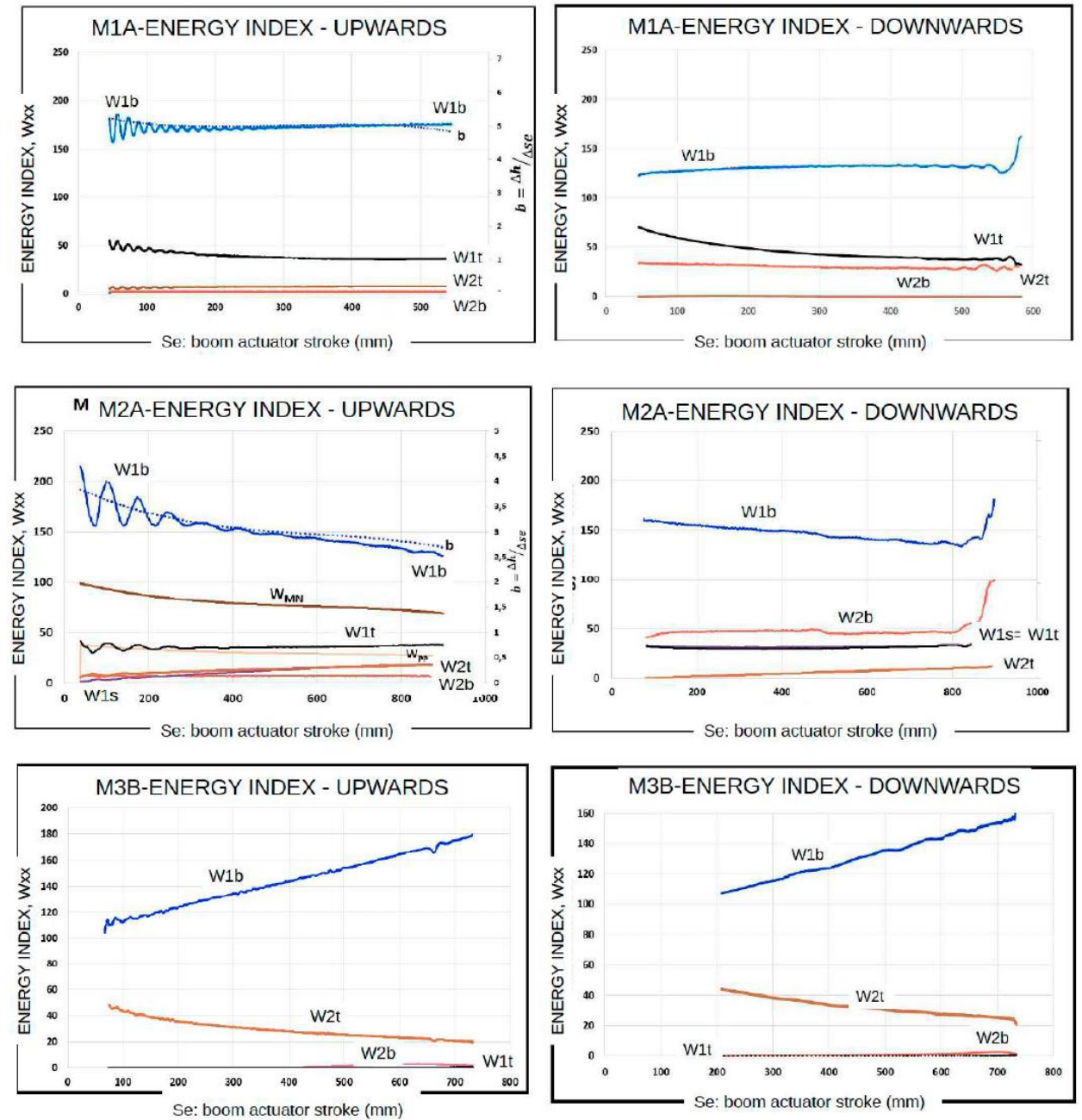

Figure 4. Graphs corresponding to the energy index, $W x$, versus the boom actuator stroke for different types of machine.

M1A: the slope of energy index $W_{1 b}$ is "zero", so the load capacity remains constant with the height of the load and power consumption is stable both up and down. (Figure 4-upper).

M2A: the slope of energy index $W_{1 b}$ is "negative", so the load capacity increases with the height of the load and power consumption is higher down than up. (Figure 4-midle).

M3B: the slope of energy index $W_{1 b}$ is "positive", so the load capacity decreases with the height of the load. And power consumption is higher up than down. (Figure 4-bottom).

The type of slope is due to the kinematics of the machine, even those that are corrected by the behaviour of pressures in the slave cylinder. This information is kinematically given by the evolution of the parameter " $\mathrm{b}$ ", and hydraulically by the evolution of the energy index $W_{1 b}$, and may be condensed into a single parameter such as the slope of the adjusted trend line.

The slope $W_{1 b}$ curve type is important for the load capacity and power balance of the machine. It is possible to achieve energy balances with all this information. 


\section{Energy Balance}

In Figure 5, some diagrams are shown that intend to visualize the energy that flows through the different elements that make up the lifting system (up and down movements) according the following equations:

1- Energy balance for lift cylinder

$$
\begin{gathered}
W_{1 b}=W_{2 b}+W_{F b}+W_{l b} \Rightarrow(\text { upwards }) \\
W_{2 b}+W_{F b}=W_{1 b}+W_{l b} \Rightarrow(\text { downwards })
\end{gathered}
$$

2- Energy balance for tilt cylinder

$$
\begin{gathered}
W_{F t}+W_{2 t}=W_{1 t}+W_{1 t} \Rightarrow(\text { upwards }) \\
W_{1 t}=W_{2 t}+W_{F t}+W_{1 t} \Rightarrow(\text { downwards })
\end{gathered}
$$

3- Energy balance for slave cylinder

$$
\begin{gathered}
W_{F s}+W_{1 s}=W_{2 s}+W_{l s} \Rightarrow(\text { upwards }) \\
W_{2 s}+W_{F s}=W_{1 s}+W_{l s} \Rightarrow(\text { downwards })
\end{gathered}
$$

4- Conditions to be met as a result of the connections (tilt/slave actuators and overcenter/check valves)

$$
\begin{gathered}
W_{2 t}=W_{2 s} \\
W_{1 t}=W_{1 s}+W_{O C V} \Rightarrow(\text { upwards }) \\
W_{1 s}=W_{1 t}+W_{C V} \Rightarrow(\text { downwards })
\end{gathered}
$$

5- Energy balance through mechanical structure (boom)

$$
\begin{gathered}
W_{F b}=W_{F s}+W_{F t}+W_{M} \Rightarrow(\text { upwards }) \\
W_{M}=W_{M N}+W_{P P}+W_{l m} \Rightarrow(\text { upwards }) \\
W_{F b}+W_{F s}=W_{F t}+W_{M} \Rightarrow(\text { downwards }) \\
W_{P P}+W_{M N}=W_{M}+W_{l m} \Rightarrow(\text { downwards })
\end{gathered}
$$

These diagrams can be adapted to the M3B machine by simply removing the $W_{o c v} / W_{c v}$ arrow that represents the energy flow through the overcenter/check valves between the tilt and slave actuators. In relation to the equations of the energy balances, it is only necessary to cancel the same terms of the expressions (23) and (24).

Figure 6 shows a representation of the energy balance corresponding to the upward and downward movements of the three proposed machines. This graph allows a comparison between them and visualization of how the different energy terms were used for the two values of the load. 

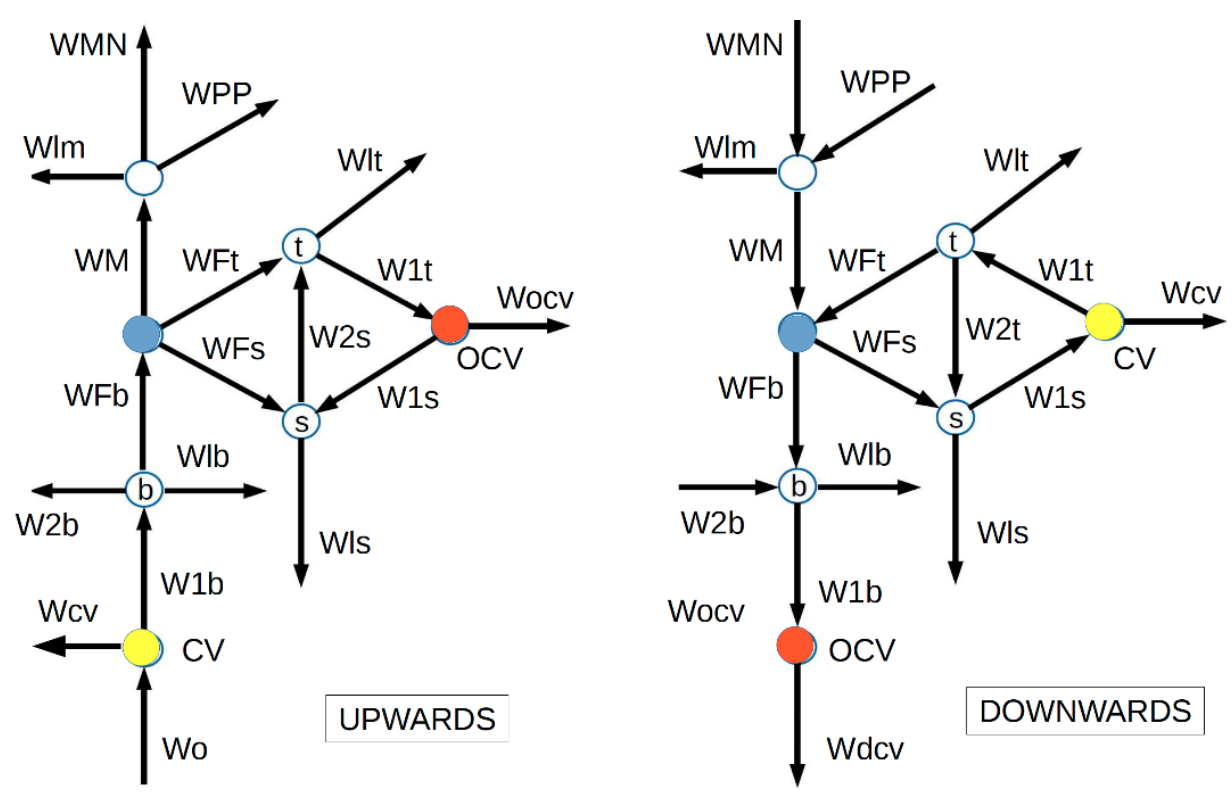

Figure 5. Energy Flow Diagrams through the different parts of the lifting system (up and down movements).

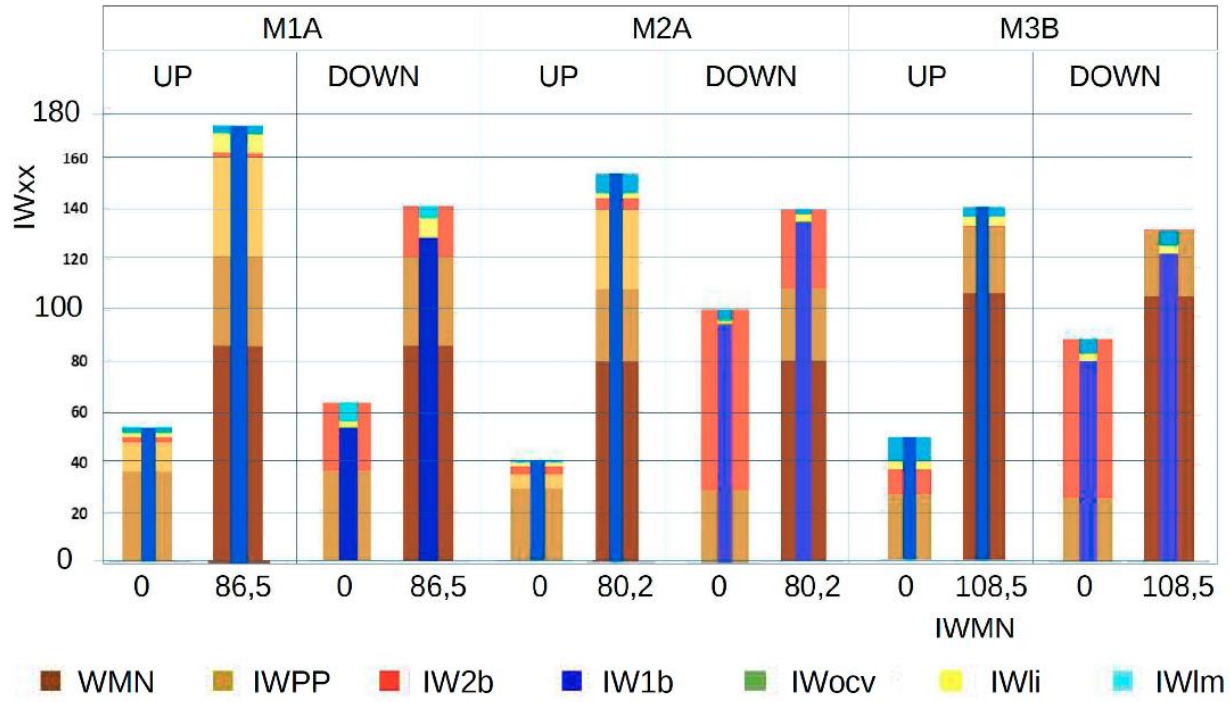

Figure 6. A graphic representation of the energy balance.

\section{Use of Average Energy Index as KPI}

As mentioned in the previous section, the average energy index $I W x\left(s e_{i}\right)$ represents the average value of the energy index of a load movement with a stroke from $s e_{1}$ to $s e_{2}$. To compare machines (from the same manufacturer or from the competition), discover weak points, and make decisions about new designs or improvements, in this paper it is proposed to use the average energy indices as key performance indicators (KPI).

For simplicity, let's make this exercise only for the machines that are presented in this paper. At this stage is important to highlight:

a. All data herein that were used comes from many research activities that were carried out along huge service that was offered to customer services from CATMech infrastructures. The data corresponds to (lab and "on-field") appliances and prototypes (research, development, and optimization activities). Each example corresponds to a complete up and down cycle, with a load constant throughout the cycle.

b. The analyzed data were chosen to expose the power of the average energy index and aid in the optimization of the design parameters. 
c. The KPI index also allows for the analyzing of innovation factors in different technological fields, such as mechanical, hydraulic, control techniques, and others.

Table 1 contains the definitions of the proposed KPIs and the calculated values for each of the three mentioned machines.

Table 1. List of the proposed key performance indicators (KPI).

\begin{tabular}{|c|c|c|c|c|c|c|}
\hline $\begin{array}{l}\mathbf{N}^{\circ} \\
\text { KPI }\end{array}$ & Definition & Symbol & & M1A & M2A & M3B \\
\hline 1 & $\begin{array}{l}\text { Permits the monitoring of the oil flow that directly flows out } \\
\text { of the rod chamber of the boom cylinder to tank through } \\
\text { the valves. }\end{array}$ & $I W_{2 b}($ up) & $\max$ & 2 & 8 & 12 \\
\hline 2 & Performs the energy required to lower a load. & $I W_{2 b}($ down $)$ & $\max$ & 30.5 & 74 & n.a. \\
\hline 3 & $\begin{array}{l}\text { Represents the percentage of energy transferred from tilt } \\
\text { cylinder to slave cylinder. }\end{array}$ & $I W_{1 s} / I W_{1 t}$ & Avrg & 0 & $45 \%$ & - \\
\hline 4 & $\begin{array}{l}\text { Related to the incoming energy in the rod chamber of the } \\
\text { tilt cylinder. }\end{array}$ & $I W_{2 t}$ & $\max$ & 12 & 28 & - \\
\hline 5 & Related to the maximum load the machine can lift. & $\Delta W_{1 b} / I W_{1 b}$ & & $41 \%$ & $0 \%$ & $-44 \%$ \\
\hline 6 & $\begin{array}{l}\text { Information about that energy that is used in raising the total } \\
\text { masses (load and self-weight of the mechanism). }\end{array}$ & $I W_{M N}$ & $\max$ & 106 & 80 & 124 \\
\hline 7 & $\begin{array}{l}\text { Points the energy used in raising the boom weight, excluding } \\
\text { the fork or bucket mass. }\end{array}$ & $I W_{M p b}$ & & 18 & 17 & 8 \\
\hline 8 & Related to the energy lost by sliding friction of the mechanism. & $I W_{l m}$ & Avrg & 2.5 & 6.5 & 6.25 \\
\hline 9 & $\begin{array}{l}\text { A measure of the cylinder's friction losses (seals friction and } \\
\text { those due to misalignments). }\end{array}$ & $I W_{l i}$ & Avrg & 5 & 1.5 & 3.2 \\
\hline 10 & $\begin{array}{l}\text { The most popular dimensionless indicator of performance of a } \\
\text { machine, independently of type and size. }\end{array}$ & $\eta$ & & $55 \%$ & $62 \%$ & $79 \%$ \\
\hline
\end{tabular}

\subsection{Comments}

\subsubsection{KPI $\mathrm{N}^{\circ} 1$-Comments about $I W_{2 b}(\mathrm{Up})$}

The results that are presented in Figure 7 (left), allow us to make the following considerations: M1A presents excellent values of the KPI, so the question is to consider if the cost reduction that is involved in downsizing is worth it, and how it can affect the value of this KPI, M2A and M3B present erratic values. These values correspond to different situations where the most significant variable had directional control valve metering or alternative regulation controls.
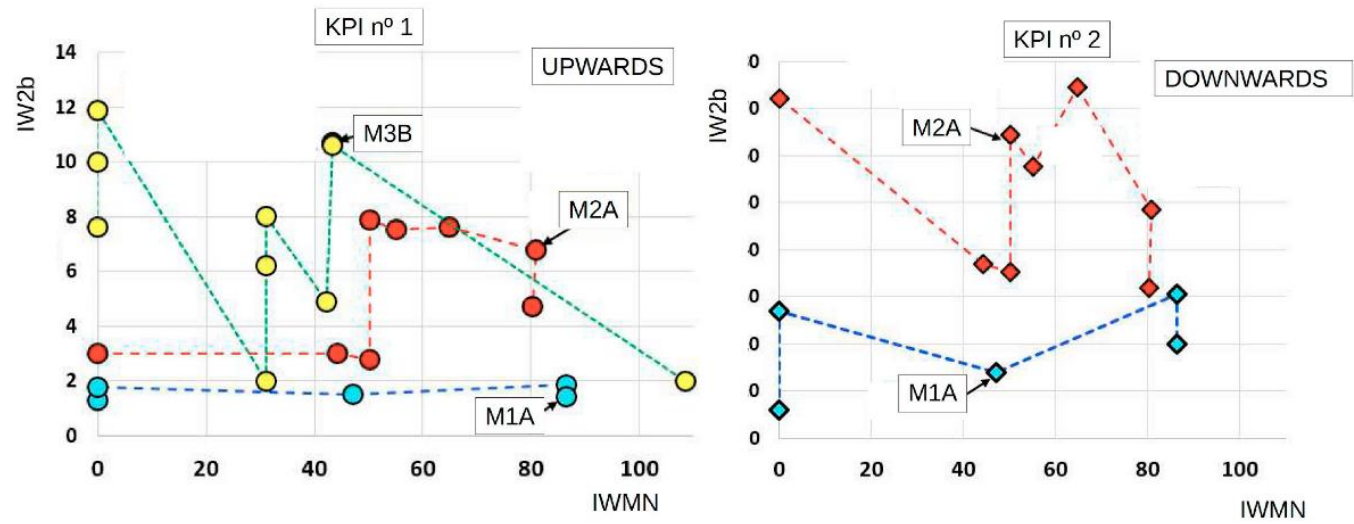

Figure 7. Graphs of the values of KPI N ${ }^{\circ} 1$ (left) and KPI N ${ }^{\circ} 2$ (right) corresponding to the machines whose data were analyzed. 
It is an indication of the return circuit impedance. In some cases, a reduced low value can be the result of a correctly designed metering spool or the result of a "standard" spool of an oversized directional control valve. As such, this indicator must be analyzed inside its context, and must be the lowest value possible with the control valve that is specifically chosen (and if it is too low, perhaps it is the occasion to reconsider if a lower valve cost is preferable).

\subsubsection{KPI N $\mathrm{N}^{\circ}$-Comments about $I W_{2 b}$ (Down)}

In Figure 7 (right), is clear that the machine M1A takes advantage over M2A due to the technology that is employed. This is related to the energy that is required to lower a load, explained by the imperative requirement of using a load holding valves for safety reasons (European Directive 98/37/CE and amendments).

\subsubsection{KPI N ${ }^{\circ} 3$-Comments about $I W_{1 s} / I W_{1 t}$}

$I W_{1 s} / I W_{1 t}$ represents the percentage of energy that is transferred from the tilt cylinder to the slave cylinder, and this is primarily due to bucket self-levelling system design (hydraulic/mechanism). If the ratio, $k_{u p}$, is less than 1 , any transfer is not possible.

$$
\begin{gathered}
Q_{2 t}=Q_{2 s} \\
k_{u p}=\frac{Q_{1 t}}{Q_{1 s}}=\frac{r_{t}}{r_{s}} \\
r_{s}=\frac{A_{1 s}}{A_{2 s}} \\
r_{t}=\frac{A_{1 t}}{A_{2 t}}
\end{gathered}
$$

This is the case of M1A, where the energy that is transferred tends to be (practically) zero, Figure 8 (left). A ratio $k_{u p}<1$ means that the flow out from the base chamber of the tilt cylinder $\left(Q_{1 t}\right)$ can't fill the base chamber of the slave cylinder with the needed flow $Q_{1 s}$. M2A has an average value of the KPI of approximately $45 \%$ that may be enhanced. The KPI3 must be considered together with $I W_{2 t}$. which is related to the energy that is required to pilot the overcenter valve of the tilt cylinder.
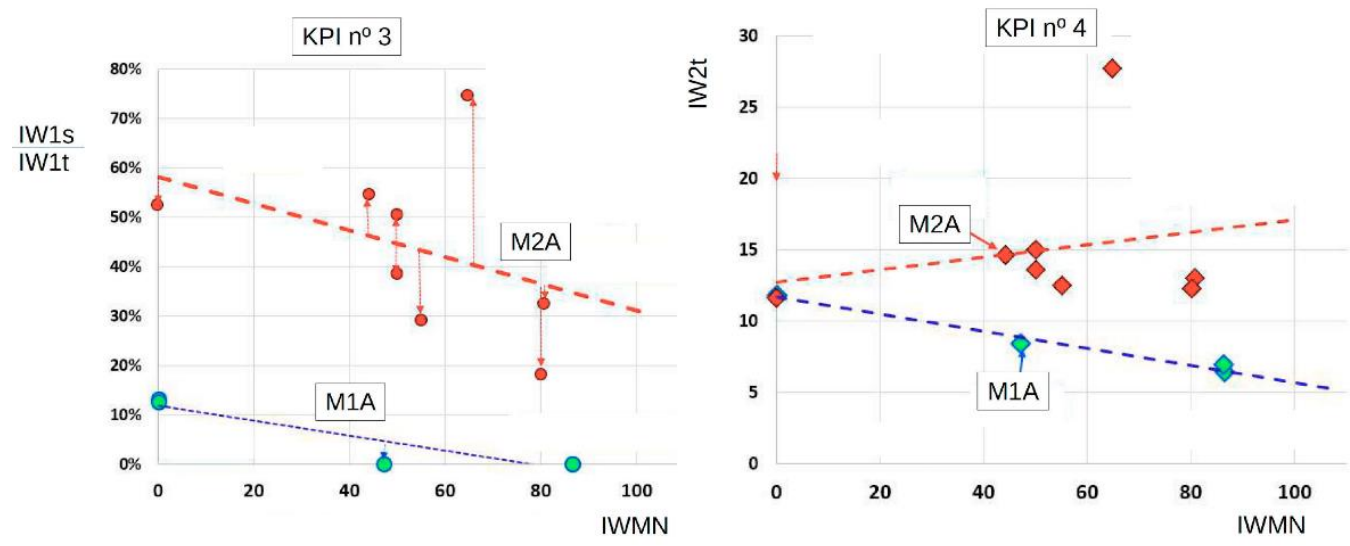

Figure 8. Graph of the values of KPI $N^{\circ} 3$ (left) and $N^{\circ} 4$ (right) corresponding to the machines whose data were analyzed.

\subsubsection{KPI N ${ }^{\circ} 4$-Comments about $I W_{2 t}$}

$I W_{2 t}$ represents the energy that is supplied to the rod chamber of the tilt cylinder and is due to the pressure that is required to pilot the overcenter valve of the tilt cylinder. A different behavior of each curve means basic differences between machines. A ratio $k_{u p}$ for M1A is $<1$ and for M2A is $>1$, Figure 8 (right). 


\subsubsection{KPI N $\mathrm{N}^{\circ}$-Comments about $\Delta W_{1 b} / I W_{1 b}$}

This index allows us to assess how $\Delta W_{1 b} / I W_{1 b}$ varies $W_{1 b}$ along the actuator stroke, as mentioned in a previous paragraph and in Figure 5. A positive value of this indicator indicates that the machine loses lifting capacity as the boom rises. Figure 9 shows the relationship between the maximum energy index $I W_{1 b}$, and $I W_{M N}$ (load to lift). The maximum energy index for M2A corresponds to the lowest position of the stroke, and for $\mathrm{M} 3 \mathrm{~B}$, corresponds to the highest. For M1A, the energy index $\mathrm{W} 1 \mathrm{~b}$, is nearly constant and coinciding with the average energy index $I W_{1 b}$. M2A did not utilize all its load capacity due to the kinematic design of the mechanism. Also, M3B, with a lower level of losses, had a higher load capacity because it has a best kinematic design, a lighter mechanical structure, and does not incorporate overcenter valves.

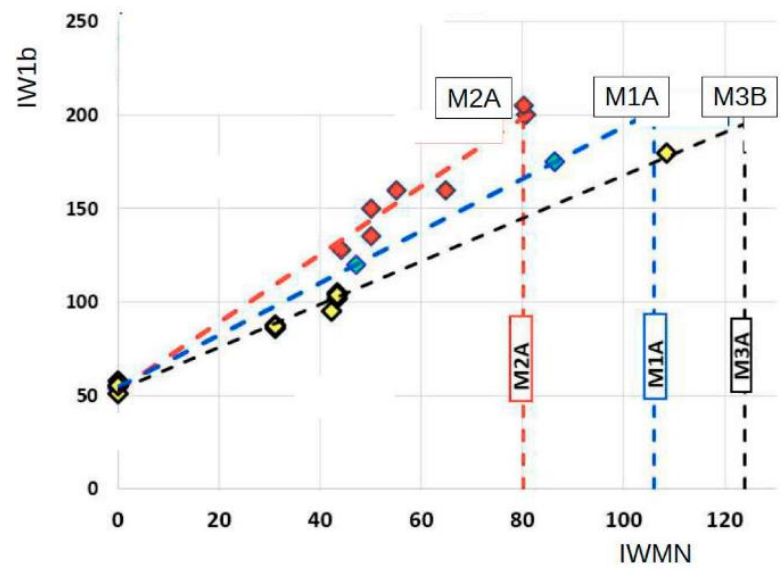

Figure 9. Graph of the values of $I W_{1 b}$ corresponding to the machines whose data were analyzed.

\subsubsection{KPI N ${ }^{\circ} 6$-Comments about $I W_{M}$}

Figure 10 shows the $I W_{M}$ that is related with the energy that is used in raising its own weight. Its value remains constant in the energy balance of each machine, both for the rise and the descent and regardless of the nominal load that is raised.
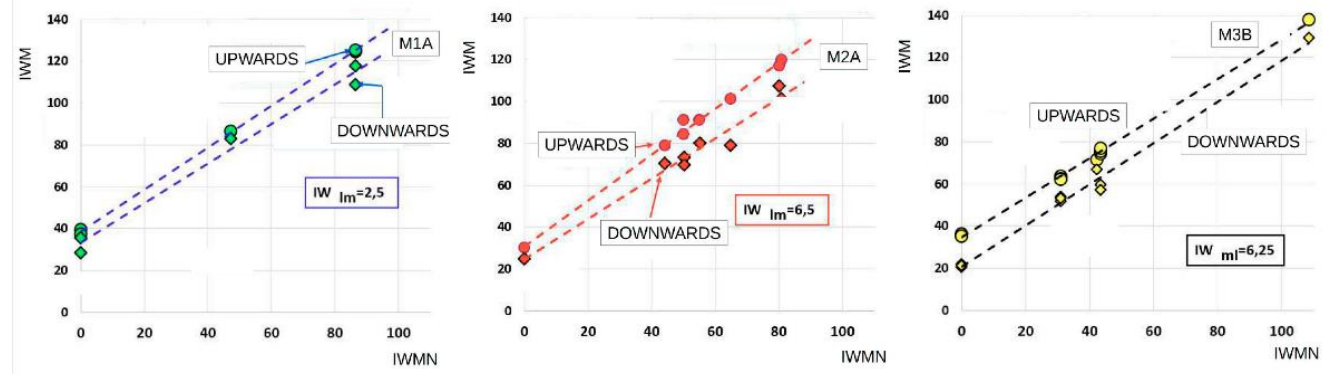

Figure 10. Graph of the values of $I W_{M}$ corresponding to the machines whose data were analyzed.

\subsubsection{KPI N ${ }^{\circ} 7$-Comments about $I W_{p b}$}

As can be seem in the Figure 6, machine M3B, has a lower index value as it corresponds to a lighter structure, and M1A and M2A have similar values, as they correspond to two machines that were designed under similar topologic designs, even if the size is different. If, eventually, the study would include other machines with a lower index value, it would mean that the manufacture technology could result in a lighter structure and could be the object of consideration and study. The utility of using dimensionless indicators is that the design technologies can be compared between different machine sizes. 


\subsubsection{KPI $N^{\circ} 8$-Comments about $I W_{l m}$}

Figure 10 shows the evolution of $I W_{M}$ (load), corresponding to the up and down movement, respectively. The difference between them is mainly due to the structural friction between the parts of the machinery that are associated with the movement.

\subsubsection{KPI N ${ }^{\circ} 9$-Comments about $I W_{l i}$}

Higher losses of M1A, are due to friction due a misalignment of the tilt cylinder (modified to incorporate an internal pressure sensor) during its assembly process in the lab, carried out by university personnel. Even though this misalignment was corrected when it was verified, it has been considered appropriate to choose these data for their didactic value, see Figure 11.

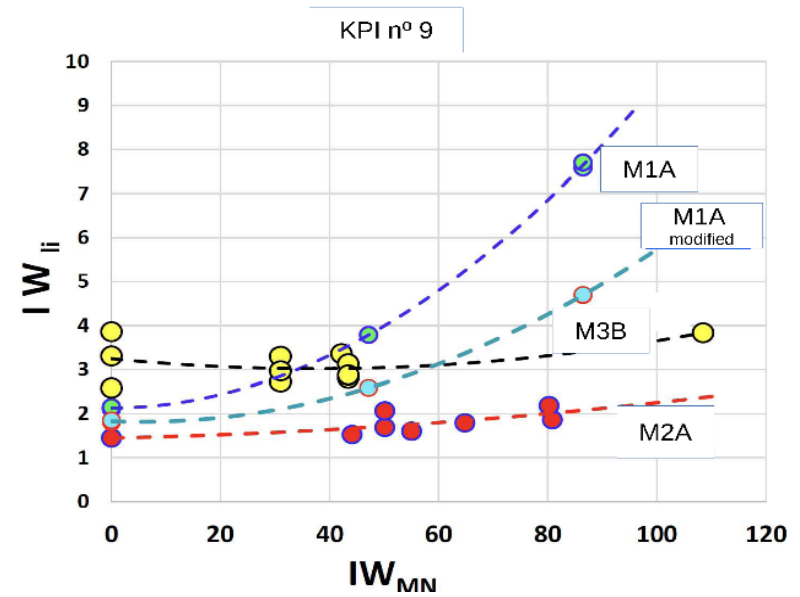

Figure 11. Graph of the values of $I W_{l i}$ corresponding to the machines whose data were analyzed.

\subsubsection{KPI N ${ }^{\circ} 10$-Comments about Efficiency}

Complementing the proposed dimensionless KPI's with the classic overall efficiency, it is possible to have a framework that allows for monitoring and decision-making in the process of an energy improvement of the machine, see Figure 12.

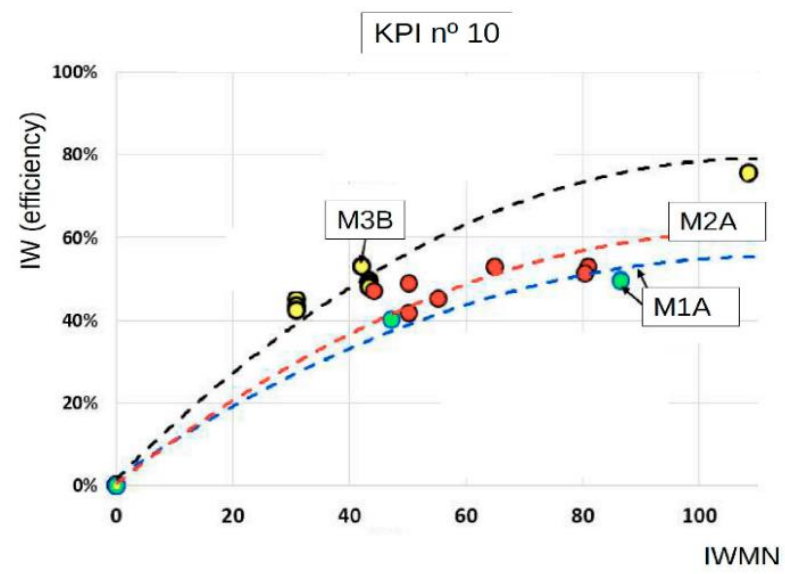

Figure 12. Graph of the values of KPI $N^{\circ} 10$ (efficiency) corresponding to the machines whose data were analyzed.

Clearly, the machine M3B, has better efficiency, due to its lighter structure and simpler hydraulic circuit without the losses that are inherent to the overcenter valves. Even when there is a certain space by improving its KPI's: $I W_{2 b}$ and $I W_{l m}$. Also, M1A and M2A, as expected, had lower efficiencies, with an improvement path through proposed KPI's. 


\section{KPI's Analysis (DASHBOARD)}

Presenting KPIs on a dashboard has become the most popular way to display and use them as a decision-making tool. Any provision is good if it serves this purpose. As an example, Figure 13 presents a simple dashboard which includes the values of the indicators with the objectives and the improvement actions.

\section{KPI'S \& OKR DASHBOARD - BENCHMARKING}

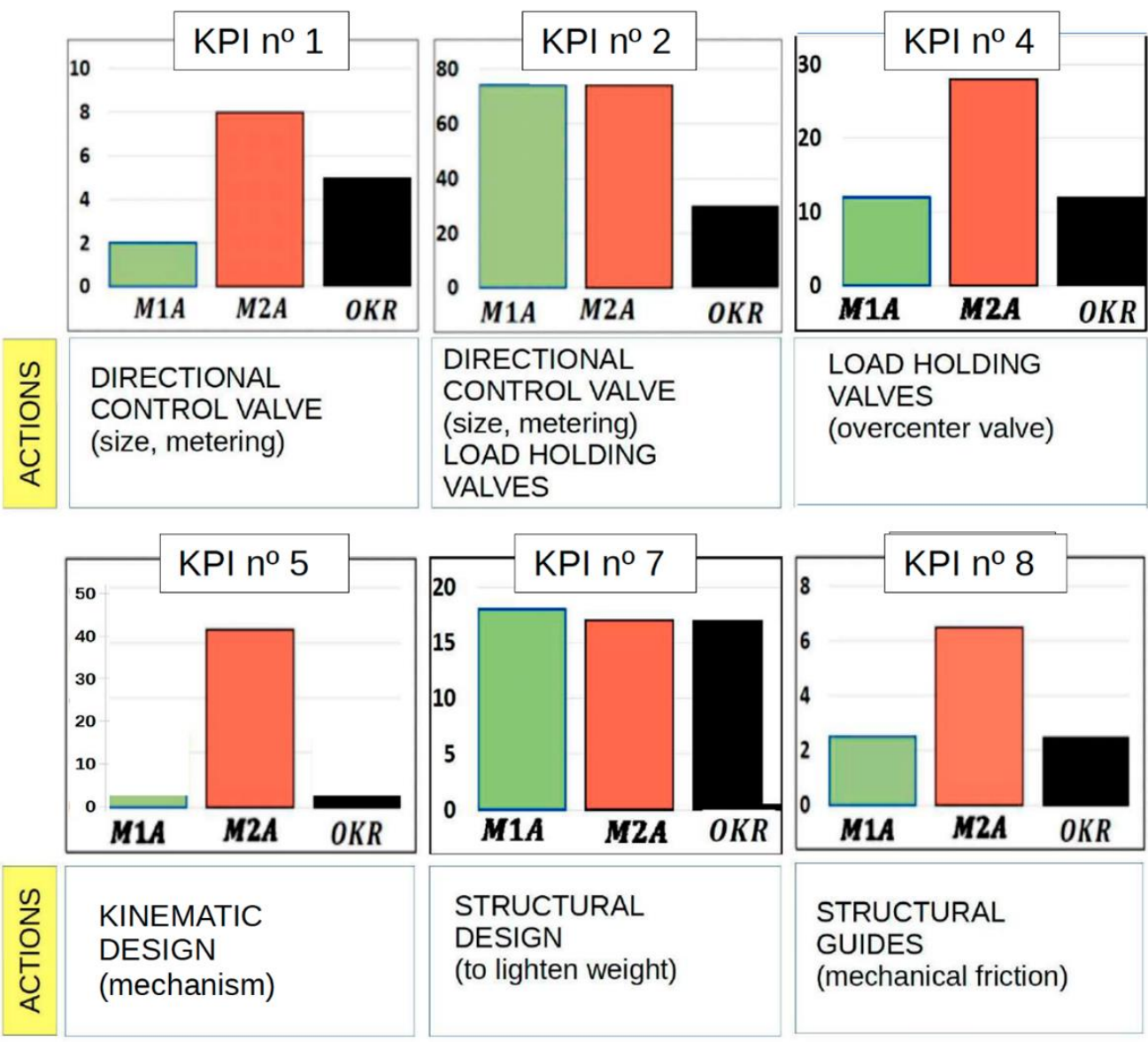

Figure 13. Dashboard of the KPIs (key performance indicators) and OKR (objectives and key results).

A first look at the efficiency graph (Figure 12) would lead us to an obvious first conclusion: the machine M3B is the most efficient of the three. This machine does not have some of the losses that are inherent in the M1A and M2A designs, such as those that are associated with overcenter valves as well as a lighter structural design.

On the other hand, comparing the efficiency of the M1A and M2A machines, we may be tempted to consider M2A slightly better (slightly higher efficiency). However, a detailed analysis of Figure 13, the values of the proposed KPIs that are shown indicate that the M2A has a high potential for improvement.

The simple principle that "if the M1A design has better indicators, the M2A design should also be able to achieve them". We refer to, for example, KPIs 1, 2, 4, and 5. That is to say, the energy indices $I W_{2 b}$ (up), $I W_{2 b}$ (down), IW $W_{1 t}$, and the ratio $\Delta W_{1 b} / I W_{1 b}$ are candidates for improvement.

Obviously, meeting these challenges may not be that simple, but it clearly indicates that these key points require the attention of designers, either to improve this machine design or for a future new prototype. 


\section{Conclusions}

This article reports a comprehensive explanation of a new methodology that is based on a set of KPI indicators to evaluate the opportunities for improvements in mobile machines. These indicators can be deduced quickly from simple energy balances using dimensionless parameters (energy index and average energy index). The example has been carried simulating the tasks of raising and lowering different loads to develop the concepts that are proposed herein.

A list of key performance indicators (KPIs) is proposed. These indicators are subcategorized according to the design and manufacture of the mechanical and hydraulic system, the control strategies, and others. All KPIs and their corollaries are reviewed concisely. The findings that were obtained from experimental results that were relevant to this study are given as a simple KPI's and OKR dashboard (Benchmarking), which includes the values of the indicators with the objectives and improvement actions.

This methodology can apply to a wide range of similar machinery independent of nominal size (of the same brand or competitors) as dimensionless parameters. The systematic application of this methodology should generate a "KPI's database" from which the following milestones can be determined:

1- Acquire a table of reference values (statistically significant and achievable). These values highlight the current state of the art technology concerning energy efficiency and the level of maturity of the technologies that are involved.

2- Expand and prioritize the list of indicators that highlight the evolution of improvement and innovation and the technologies that make it possible

3- Define the design criteria and recommendations that allow estimating the mechanical and hydraulic friction into others, and then what can we expect (or extrapolate) from a new prototype.

Addressing these milestones will be the subject of future research.

Author Contributions: The investigation was led and supervised by E.C. and P.R. Experimental works, models, data processing, and illustrations were completed by G.R., L.J.B., P.R., P.-J.G.-M. and E.C. The manuscript was finalized by G.R., E.C., P.R. and P.-J.G.-M. All authors have read and agreed to the published version of the manuscript.

Funding: This research received external funding. Data of the front loader originated in the prototype that was built up by BMH during the research activities in the framework of PROHIPP project, partially financed by EU (2004-2008), and LEVANTE project, partially financed by IBEROEKA program (2002-2005).

Institutional Review Board Statement: Not applicable.

Informed Consent Statement: Not applicable.

Data Availability Statement: The data presented in this study are available on request from the corresponding author. The data are not publicly available due to privacy reasons.

Acknowledgments: Our gratitude to the entities that have lent their machines to evaluate their behavior, during our R\&D activities, especially AUSA (Manresa-Spain) and Palas BMH (PoleñinoSpain). Also, the Roquet Group and IHBER, who provided important hydraulic devices that were used in the research. Part of this research was dedicated to investigating the influence and contribution to the behavior of the machine of different components and systems designs. These investigations and data have been the trigger for the modelling of the proposed KPIs and the basis their validation.

Conflicts of Interest: The authors declare no conflict of interest. 


\section{Nomenclature}

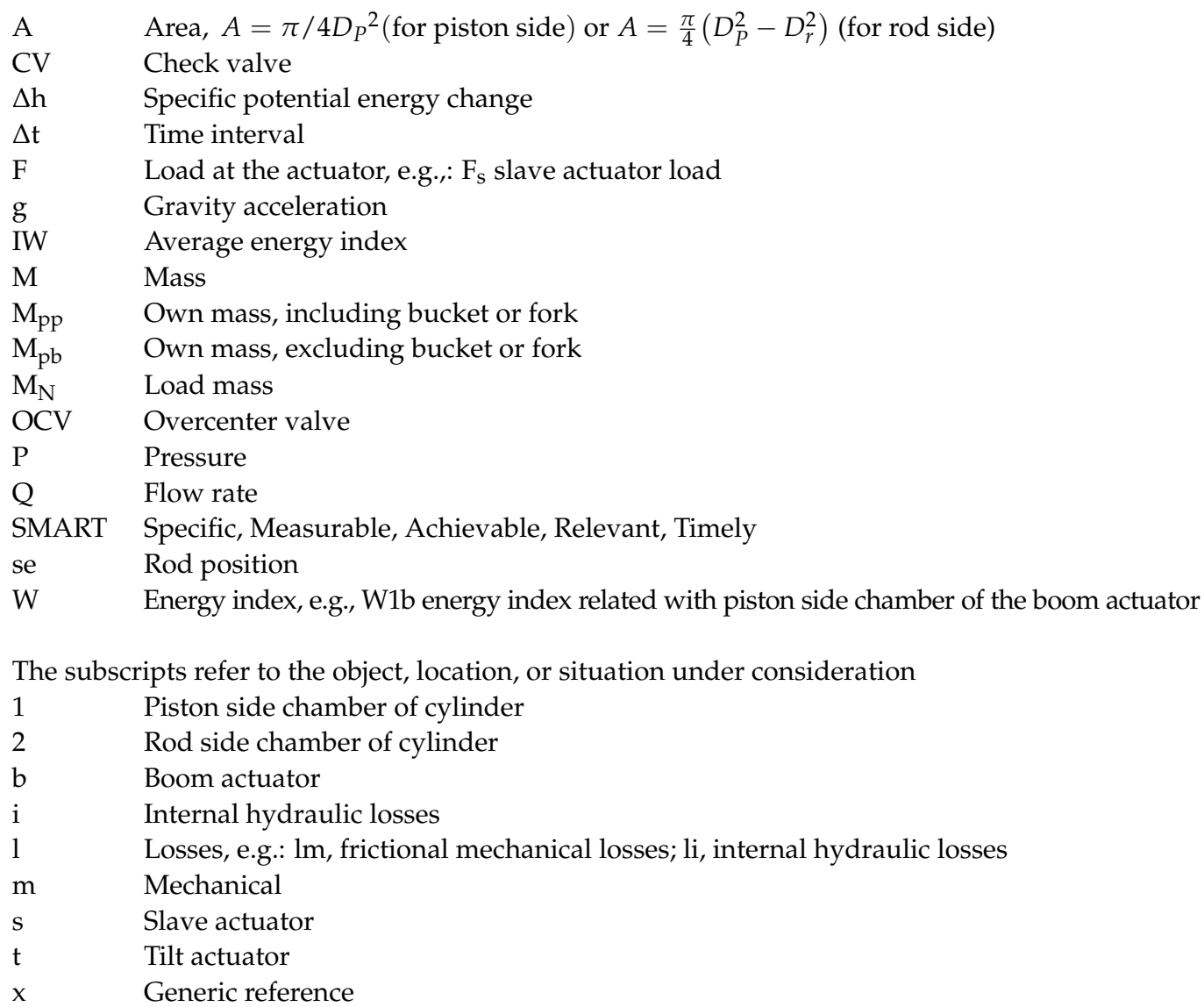

\section{References}

1. European Commission. COM(2010) 2020 Final, Europe 2020: A Strategy for Smart, Sustainable and Inclusive Growth. Available online: http: / / eur-lex.europa.eu/LexUriServ/LexUriServ.do?uri=COM:2010:2020:FIN:EN:PDF (accessed on 11 January 2022).

2. Karpenko, M.; Bogdevičius, M. Review of Energy-saving Technologies in Modern Hydraulic Drives. Moksl.-Liet. Ateitis 2017, 9 , 553-558. [CrossRef]

3. Yu, Y.; Jeong, E.; Ahn, K.K. Review of Energy Saving Technology of Hybrid Construction Machine. J. Drive Control 2018, 15, 91-100. [CrossRef]

4. Berne, L.J.; Raush, G.; Gamez-Montero, P.J.; Roquet, P.; Codina, E. Multi-Point-of-View Energy Loss Analysis in a Refuse Truck Hydraulic System. Energies 2021, 14, 2707. [CrossRef]

5. Roquet, P.; Gamez-Montero, P.; Castilla, R.; Raush, G.; Codina, E. A Simplified Methodology to Evaluate the Design Specifications of Hydraulic Components. Appl. Sci. 2018, 8, 1612. [CrossRef]

6. Mahato, A.C.; Ghoshal, S.K. Energy-saving strategies on power hydraulic system: An overview. Proc. Inst. Mech. Eng. Part I J. Syst. Control Eng. 2021, 235, 147-169. [CrossRef]

7. Greenwood, R.G. Management by Objectives: As Developed by Peter Drucker, Assisted by Harold Smiddy. Acad. Manag. Rev. 1981, 6, 225. [CrossRef]

8. Deming, W.E. Out of the Crisis, 1st ed.; MIT Press: Cambridge, MA, USA, 1986; ISBN 0-911379-01-0.

9. Brim, R. A Management by Objectives History and Evolution. Available online: http://www.performancesolutionstech.com/ FromMBOtoPM.pdf (accessed on 11 January 2022).

10. Hansen, B. KPIs vs. OKRs: How They Compare and Why You Need Both to Be Successful. Available online: https://www.wrike. com/blog/kpis-vs-okrs-compare-need-successful/ (accessed on 28 January 2022).

11. Lindberg, C.-F.; Tan, S.; Yan, J.; Starfelt, F. Key Performance Indicators Improve Industrial Performance. Energy Procedia 2015, 75, 1785-1790. [CrossRef]

12. May, G.; Barletta, I.; Stahl, B.; Taisch, M. Energy management in production: A novel method to develop key performance indicators for improving energy efficiency. Appl. Energy 2015, 149, 46-61. [CrossRef]

13. May, G.; Taisch, M.; Prabhu, V.V.; Barletta, I. Energy related key performance indicators-state of the art, gaps and industrial needs. In IFIP International Conference on Advances in Production Management Systems; Springer: Berlin/Heidelberg, Germany, 2013; pp. 257-267. [CrossRef] 
14. Osman, M.; Abokersh, M.H.; El-Baz, O.; Sharaf, O.; Mahmoud, N.; El-Morsi, M. Key performance indicators (KPIs): Assessing the process integration of a shell-and-tube latent heat storage unit. J. Clean. Prod. 2020, 256, 120249. [CrossRef]

15. Tambare, P.; Meshram, C.; Lee, C.-C.; Ramteke, R.J.; Imoize, A.L. Performance Measurement System and Quality Management in Data-Driven Industry 4.0: A Review. Sensors 2021, 22, 224. [CrossRef]

16. Rivas, J.R. Accionamiento y Control del Posicionado de Aperos Agrícolas Mediante Actuadores Oleo Hidráulicos. Ph.D. Thesis, Universitat Politècnica de Catalunya, Terrassa, Spain, 2004. 